\title{
Binding of Serotonin to Receptors at Multiple Sites Is Required for Structural Plasticity Accompanying Long-Term Facilitation of Aplysia Sensorimotor Synapses
}

\author{
Zhong-Yi Sun and Samuel Schacher \\ Center for Neurobiology and Behavior, Columbia University College of Physicians and Surgeons, and New York State \\ Psychiatric Institute, New York, New York 10032
}

Long-term changes in the efficacy of Aplysia sensorimotor synapses accompany nonassociative and associative forms of behavioral plasticity. This synapse expresses long-term facilitation either with repeated applications of 5-hydroxytryptamine (5-HT) or with a single pairing of tetanus in the sensory neuron (SN) and bath application of 5-HT. We examined whether structural changes in the $\mathrm{SN}$ accompany all forms of long-term synaptic enhancement and the locations at which 5-HT must bind receptors to evoke long-term functional and/or structural changes. Pairing tetanus with one application of 5-HT evoked both functional and structural changes after $24 \mathrm{hr}$ only when 5-HT application was temporally paired with the tetanus and activated receptors on both the $\mathrm{SN}$ cell body and terminal region. Repeated application of $5-\mathrm{HT}$ to the terminal region alone failed to evoke any long-term change. Repeated applications of 5-HT to the SN cell body alone evoked a change in synaptic efficacy at $24 \mathrm{hr}$ but failed to increase SN varicosities. Repeated applications of 5-HT to both the SN cell body and the terminal region evoked increases in both synaptic efficacy and the number of SN varicosities at $24 \mathrm{hr}$. The results indicate that different external stimuli can evoke equivalent forms of longterm synaptic facilitation with or without structural changes in the SNs. Changes in the number of SN varicosities can accompany different forms of long-term facilitation and require the activation of 5-HT receptors at multiple sites.

Key words: long-term; synaptic plasticity; activity-dependent plasticity; 5-HT; structure-function relationships; sensory neuron; Aplysia
Change in synaptic efficacy is one cellular mechanism mediating experience-dependent changes in behavior. The duration of synaptic plasticity is governed by the activation of specific second messenger cascades and the induction of new gene expression (Goelet et al., 1986; Malenka et al., 1989; Bartsch et al., 1995; Yin et al., 1995). Although short-term changes in synaptic efficacy do not require new macromolecular synthesis, the same second messenger cascades may contribute to both short- and long-term synaptic plasticity (Kandel and Schwartz, 1982; Byrne et al., 1993). The nature of the external stimuli and their sites of action required to trigger cell and molecular processes associated with short- versus long-term synaptic plasticity and the intracellular machinery critical for expressing short- versus long-term change are poorly understood.

The synapses of Aplysia sensory neurons (SNs) express shortand long-term increases in efficacy that correlate with short- and long-term sensitization and the classical conditioning of defensive withdrawal reflexes (Castellucci and Kandel, 1976; Hawkins et al., 1983; Walters and Byrne, 1983; Frost et al., 1985). Long-term sensitization also is accompanied by structural changes in the SN synapses, including an overall increase in the number of $\mathrm{SN}$

\footnotetext{
Received Dec. 30, 1997; revised March 6, 1998; accepted March 10, 1998.

This research was supported by National Institutes of Health Grant GM 32099 Animals were provided by the National Center for Research Resources, National Resource for Aplysia, at the University of Miami under National Institutes of Health Grant RR 10294. We thank Eve Vagg and Rachel Yarmolinsky for assistance in preparing the figures and Drs. J. Koester and I. Kupfermann for comments on earlier drafts of this manuscript.

Correspondence should be addressed to Dr. Samuel Schacher, Center for Neurobiology and Behavior, Columbia University College of Physicians and Surgeons, New York State Psychiatric Institute, 722 West 168th Street, New York, NY 10032. Copyright (C) 1998 Society for Neuroscience 0270-6474/98/183991-10\$05.00/0
}

varicosities (Bailey and Chen, 1983, 1988). These long-term functional and structural changes can be simulated by repeated applications of 5-hydroxytryptamine (5-HT) (Montarolo et al., 1986; Glanzman et al., 1990; Clark and Kandel, 1993; Emptage and Carew, 1993) or by direct intracellular injections of cAMP into the SN cell body (Nazif et al., 1991; Schacher et al., 1993; O'Leary et al., 1995). Repeated applications of 5-HT at short intervals lead to the translocation of protein kinase A (PKA) and other kinases into the $\mathrm{SN}$ nucleus, triggering a complex program of early and late gene expression that contributes to changes in excitability, the growth of new SN branches, and the formation of new synaptic connections (Kandel and Schwartz, 1982; Greenberg et al., 1987; Schacher et al., 1988; Scholz and Byrne, 1988; Dash et al., 1990; Backsai et al., 1993; Byrne et al., 1993; Alberini et al., 1994; Bartsch et al., 1995; Martin et al., 1997b; Zhang et al., 1997).

The changes in the SN cell body and nucleus evoked by the activation of local 5-HT receptors may be sufficient to account for all of the long-term functional and structural changes at SN synaptic terminals. Although short-term facilitation of SN synapses requires the activation of 5-HT receptors at or near $\mathrm{SN}$ synaptic terminals (Clark and Kandel, 1984; Emptage and Carew, 1993; Sun et al., 1996), long-term facilitation of sensorimotor synapses in the intact nervous system can be evoked by applications of 5-HT to the SN cell body alone (Clark and Kandel, 1993; Emptage and Carew, 1993). When higher concentrations of 5-HT are used, long-term facilitation also is expressed when 5-HT is applied to the terminal regions alone (Clark and Kandel, 1993; Emptage and Carew, 1993). However, in the intact nervous system, one cannot control for endogenous release of 5-HT (or other neuromodulators) from a high density of 5-HT-positive terminals in contact with SN cell bodies (Kistler et al., 1985; 
Zhang et al., 1991). Thus, it is difficult to determine the contribution of 5-HT-activated receptors and signal transduction machinery at each location (SN cell body and terminals) to the functional and structural changes accompanying long-term facilitation.

It is possible to reconstitute the sensorimotor synapse in cell culture and focally apply 5-HT to specific regions (Sun et al., 1996). Sun et al. (1996) reported that 5-HT receptors are enriched at the $\mathrm{SN}$ cell body and at $\mathrm{SN}$ varicosities contacting the proximal motor axon. Using this approach, we report that the application of 5-HT to different sites can evoke different forms of long-term synaptic facilitation with or without structural changes in the SNs. Change in the structure of SNs accompanies different forms of long-term facilitation and requires the activation of 5-HT receptors on both the $\mathrm{SN}$ cell body and terminal region. Long-term facilitation $(>24 \mathrm{hr})$ can be evoked with 5 -HT applications to the $\mathrm{SN}$ cell body alone, but without changes in the structure of the SN.

\section{MATERIALS AND METHODS}

Cell culture. SNs of Aplysia were isolated from the pleural ganglion of adult animals $(70-100 \mathrm{gm})$, cocultured with identified motor cell L7 isolated from the abdominal ganglion of juvenile animals (1-3 gm; University of Miami Aplysia Mariculture Facility), and maintained for $5 \mathrm{~d}$ as described previously (Schacher and Proshansky, 1983; Schacher, 1985; Rayport and Schacher, 1986). Each L7 was isolated with the proximal segment $(400-700 \mu \mathrm{m})$ of its original axon (Schacher and Proshansky, 1983). Each culture contained a single SN cocultured with a single L7. Cells were allowed to regenerate for $4 \mathrm{~d}$ to permit the formation of stable synaptic contacts and neuritic arbors (Montarolo et al., 1986; Glanzman et al., 1990; Schacher and Montarolo, 1991).

Electrophysiology. The stimulation and recording techniques for measuring long-term changes in the efficacy of the SN-L7 connection after treatments with 5-HT or activity have been described (Montarolo et al., 1986, 1988; Schacher et al., 1997). For monitoring changes in synaptic efficacy, the motor cell was impaled with a microelectrode (10-15 M $\Omega$ ) containing $2.0 \mathrm{M} \mathrm{K}$-acetate, $0.5 \mathrm{M} \mathrm{KCl}$, and $10 \mathrm{~mm} \mathrm{~K}$-HEPES, pH 7.4. The motor cell $\mathrm{L} 7$ was maintained at $-80 \mathrm{mV}$ for measuring the EPSP amplitude at both time points. For each coculture, synaptic potentials were evoked in L7 by stimulating the SN with a brief $(0.3-0.5 \mathrm{msec})$ depolarizing pulse, using an extracellular electrode (Montarolo et al., 1988). During the recording, dye filling (see below), or treatments with 5-HT, cultures were superfused at $1 \mathrm{ml} / \mathrm{min}$ with L15-seawater medium consisting of artificial seawater (Instant Ocean) and modified L15 with salt concentrations added to levels consistent with seawater (perfusion medium). After recording and dye injection, 5-HT was applied (see below) either $4 \times$ at $25 \mathrm{~min}$ intervals, with each application lasting $5 \mathrm{~min}$ (Montarolo et al., 1986), or applied once for 3 or $5 \mathrm{~min}$ in association with a brief tetanus to the SN ( $20 \mathrm{~Hz}$ for $2 \mathrm{sec})$. 5-HT was applied paired with tetanus (beginning $0.5 \mathrm{sec}$ after the onset of the tetanus; Eliot et al., 1994; Schacher et al., 1997) or in an unpaired manner (backward or forward; see Results).

Transmitter applications. 5-HT was applied focally by pressure ejection via a micropipette containing $50 \mu \mathrm{M}$ 5-HT and $0.02 \%$ Fast Green to visualize the location of the stream (Stoop and Poo, 1995; Sun et al., 1996) (Fig. 1). A second micropipette attached to a vacuum was positioned near the ejection pipette for the rapid removal of neuromodulator. The width of the stream across the selected region of interest was controlled by the placement of the pipettes containing 5-HT and the one attached to the vacuum used to remove the 5-HT (Fig. 1). 5-HT was applied for 3 or 5 min to one of three areas: (1) to the SN cell body (Fig. $1 A)$, (2) to the initial $350-400 \mu \mathrm{m}$ segment of the motor axon that is the region containing the most proximal portion of the SN arbor (Fig. $1 B$ ) (Glanzman et al., 1989; Bank and Schacher, 1992; Zhu et al., 1997), or (3) to both the SN cell body and the initial $350-400 \mu \mathrm{m}$ segment of the motor axon (Fig. 1C). We ruled out spillover of 5-HT to the SN cell body when it was applied to the motor axon and SN terminals by monitoring for 5-HT-induced changes in excitability (Sun et al., 1996). No change was detected immediately after a 5 min application to $\mathrm{SN}$ neurites and terminals in contact with the motor axon. A fourfold increase in excitability was observed after 5-HT application to the SN cell body. Applications of 5-HT to the motor axon (while held at $-60 \mathrm{mV}$ ) evoked small

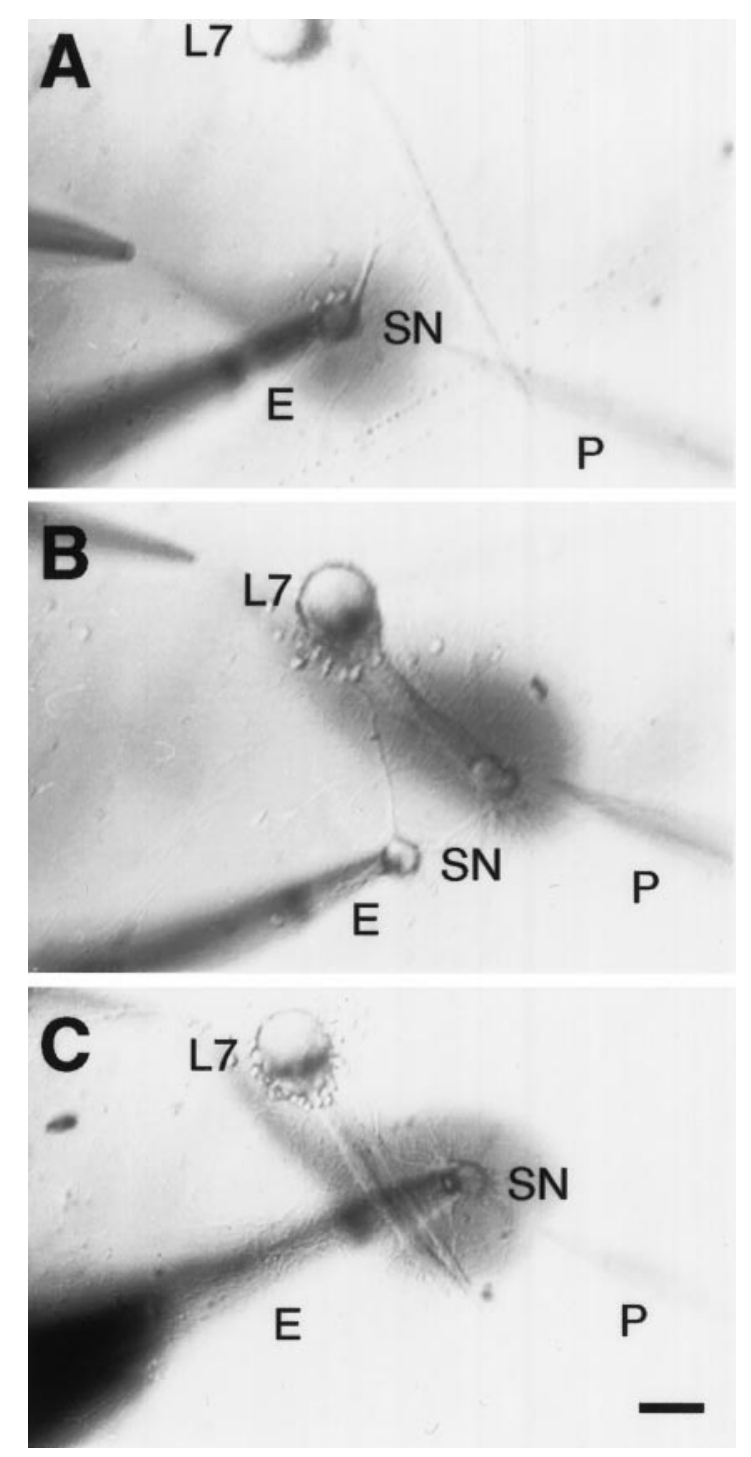

Figure 1. Application of 5-HT to different areas of interaction between the sensory neuron $(S N)$ and L7. Phase-contrast micrographs of three cocultures each, with a single $\mathrm{SN}$ forming synaptic contacts with a single L7. The axon of L7 emerges from the cell body (top of each micrograph) and extends toward the lower right. The stump of the SN axon is always placed next to the axon of L7 so that the proximal arbor of the SN contacts the proximal axon of L7. Pressure is used to eject 5-HT plus Fast Green from the pipette $(P)$ at right, and rapid suction is used to remove solution from the pipette at left. 5-HT solution is added to specific regions of SN-L7 interaction by positioning the pipettes at appropriate locations so that 5-HT binds to receptors on the SN cell body $(A)$, to receptors on the terminals in the proximal portion of the SN arbor that are in contact with the axon of L7 $(B)$, or to receptors on both the SN cell body and terminal region $(C)$. $E$ indicates the extracellular electrode used to stimulate SN (single action potential or tetanus). Scale bar, $50 \mu \mathrm{m}$.

(1-2 $\mathrm{mV}$ ) hyperpolarizations in the membrane potential of L7. In addition, 5-HT evoked little or no detectable change in L7 membrane conductance $(0$ to $\pm 10 \%)$.

Dye injection and imaging $S N$ neurites and varicosities. After recording the amplitude of the EPSP on each day, the same individual injected fluorescent dye 5(6)-carboxyfluorescein $(6 \%$ in $0.44 \mathrm{~m} \mathrm{KOH}, \mathrm{pH} \mathrm{7.0;}$ Molecular Probes, Eugene, OR) into the SN with 0.4-0.6 nA hyperpolarizing current pulses $(500 \mathrm{msec}$ at $1 \mathrm{~Hz})$ for 6 min (Glanzman et al., 1989, 1990; Schacher and Montarolo, 1991). Nomarski or phase-contrast and fluorescent images of the same view areas along the axons of L7 were taken to map out the location of SN neurites and varicosities at each time point (days 4 and 5). Images were taken with a Nikon Diaphot micro- 


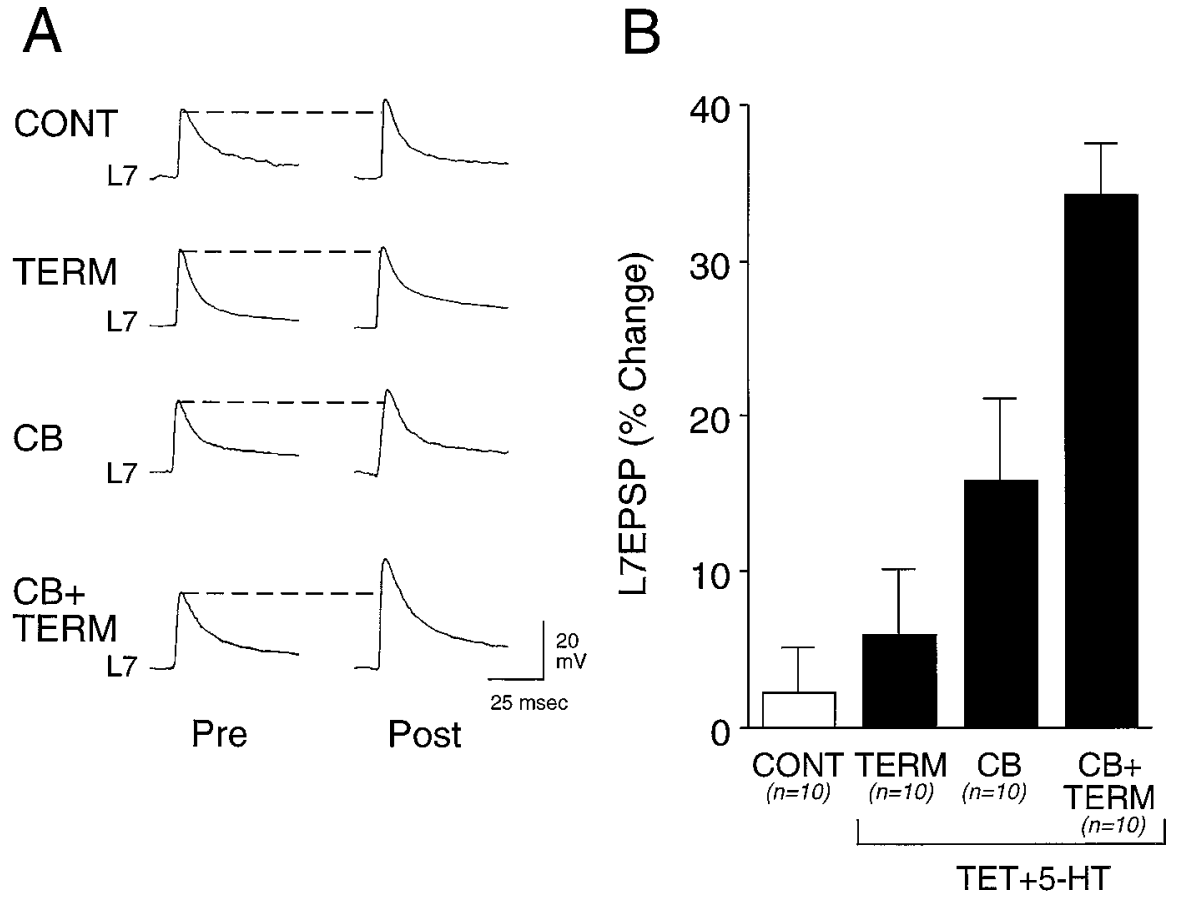

Figure 2. Pairing tetanus with 5-HT application to both the SN cell body and terminal region evoked long-term facilitation. $A$, Examples of EPSPs evoked before (Pre) and $24 \mathrm{hr}$ after (Post) 1× application of control solution (Fast Green) to the SN cell body and terminal region (CONT), $1 \times$ pairing of tetanus with 5-HT to terminal region (TERM), $1 \times$ pairing of tetanus with 5 -HT to the SN cell body $(C B)$, or $1 \times$ pairing of tetanus with 5-HT to both cell body and terminal region $(C B+$ $T E R M) . B$, Summary of the percentage of change in EPSP amplitude $24 \mathrm{hr}$ after treatments. The height of each bar is the mean \pm SEM percentage of change per culture ( $n=10$ for each group). ANOVA $\left(F_{(3,36)}=12.301 ; p<0.001\right)$ and multicomparison Scheffé's $F$ tests indicated that only pairing tetanus with 5-HT to $C B+T E R M$ evoked significant change as compared with other treatments $(F=10.001, p<0.01$ vs control; $F=7.770$, $p<0.01$ vs 5 -HT applied to terminal region; $F=$ $3.733, p<0.03$ vs 5 -HT applied to $\mathrm{SN}$ cell body). scope attached to a SIT (Dage 68) video camera, processed by a Dell 310 computer with a PC Vision Plus frame grabber, and subsequently stored on a Panasonic optical disk drive. Alignment of the live view area at the second time point with the initial recorded image was aided by the computer, with fine adjustments made with the stage controls and by manual rotation of the culture dish. The illumination used for obtaining fluorescent images was kept as low as possible to prevent photo damage (Glanzman et al., 1990; Schacher and Montarolo, 1991; Bailey et al., 1992; Schacher et al., 1993; Zhu et al., 1995, 1997). In general, the same illumination levels were used at both time points to minimize the differences in imaged structures that might arise as a result of differences in the extent of dye filling, and light intensities used at the second time point were adjusted slightly $( \pm 10 \%)$ to match the intensity of the stored images taken before treatment. Micrographs of the images were made with a Panasonic or Sony video printer.

Quantifying structural changes. Counts of varicosity number were obtained from fluorescent images of SN neurites contacting the proximal $350-400 \mu \mathrm{m}$ of the axon of L7, the region of the SN-L7 interaction that was exposed to the stream of 5-HT and closest to the SN cell body. Previous studies had indicated that this portion of the L7 axon is the most favorable substrate for the growth of SN neurites that form varicosities with transmitter release sites (Glanzman et al., 1989, 1990; Schacher et al., 1990a). Varicosities contacting distant motor neurites do not contain active zones (Glanzman et al., 1989, 1990). Because the axon of L7 is a relatively thick structure, it often required as many as four different focal planes to image all of the labeled neurites and varicosities in a given view area. To minimize slight differences in focus which could obscure differences in varicosity number, we used computer-assisted superimposition of the various focal planes onto a single two-dimensional image. The matched fluorescent images of each focal plane along with the superimpositions for both time points were compared, and the total number of varicosities was counted. A varicosity (swelling along a sensory cell process $>2 \mu \mathrm{m}$ in diameter) was considered new if the structure was not observed within a $2 \mu \mathrm{m}$ radius on the image of the same view area taken $24 \mathrm{hr}$ earlier. Structures that were slightly elongated spheres $\geq 2 \mu \mathrm{m}$ connected by narrow neuritic necks were counted as varicosities (Bailey and Chen, 1983, 1988). Although the dye injections were not performed blind, the counts of varicosities were performed blind. The individual did not know the amplitude of the EPSPs before or after treatment or the nature of the treatment. Only net change in varicosity number (not changes in varicosity shape) was used to measure structural changes evoked with treatments.

\section{RESULTS}

A single temporal pairing of a tetanus in the $\mathrm{SN}$ with bath application of 5-HT evokes short-term enhancement of sensorimotor synapses in culture that outlasts the change in efficacy evoked by 5-HT or tetanus alone (Eliot et al., 1994; Bao et al., 1997). The same paired stimuli also evokes a long-term change $(24 \mathrm{hr}$ ) in the efficacy of sensorimotor synapses that is similar in magnitude to the change evoked by four repeated applications of 5-HT (Schacher et al., 1997). We first examined whether the expression of long-term functional change requires 5-HT activation of receptors on both the $\mathrm{SN}$ cell body and $\mathrm{SN}$ terminals contacting the proximal motor axon. We then examined whether expression of long-term facilitation required the temporal pairing of the two stimuli.

\section{Long-term functional changes are evoked by temporal pairing of tetanus activity in the SN and 5-HT activation of receptors on both the $\mathrm{SN}$ cell body and terminal region}

Significant change in the efficacy of sensorimotor synapses is evoked when tetanus (TET) is paired with a 5 min application of 5-HT to the SN cell body and terminal region (Fig. 2). Application of 5-HT to both regions $(C B+T E R M)$ resulted in a $35.3 \pm$ $3.3 \%$ change in the amplitude of the EPSP recorded $24 \mathrm{hr}$ after treatment. This is significantly greater $(p<0.01)$ than the change of $2.2 \pm 3.0 \%$ evoked with applications of Fast Green alone $(C O N T)$. Application of 5-HT to both regions also evoked a change that is significantly greater $(p<0.01)$ than the change of $6.0 \pm 4.1 \%$ evoked with pairing tetanus with 5 -HT application to the terminal region alone $(T E R M)$ or the change of $15.8 \pm 5.3 \%$ $(p<0.03)$ evoked by pairing tetanus with 5-HT application to the $\mathrm{SN}$ cell body alone $(C B)$. Although application of 5-HT to the cell body alone evoked a change $>20 \%$ in 3 of the 10 cultures, the overall effect was not significantly different from the change evoked by control treatment $(p>0.15)$.

Temporal pairing of the two stimuli is required for long-term 


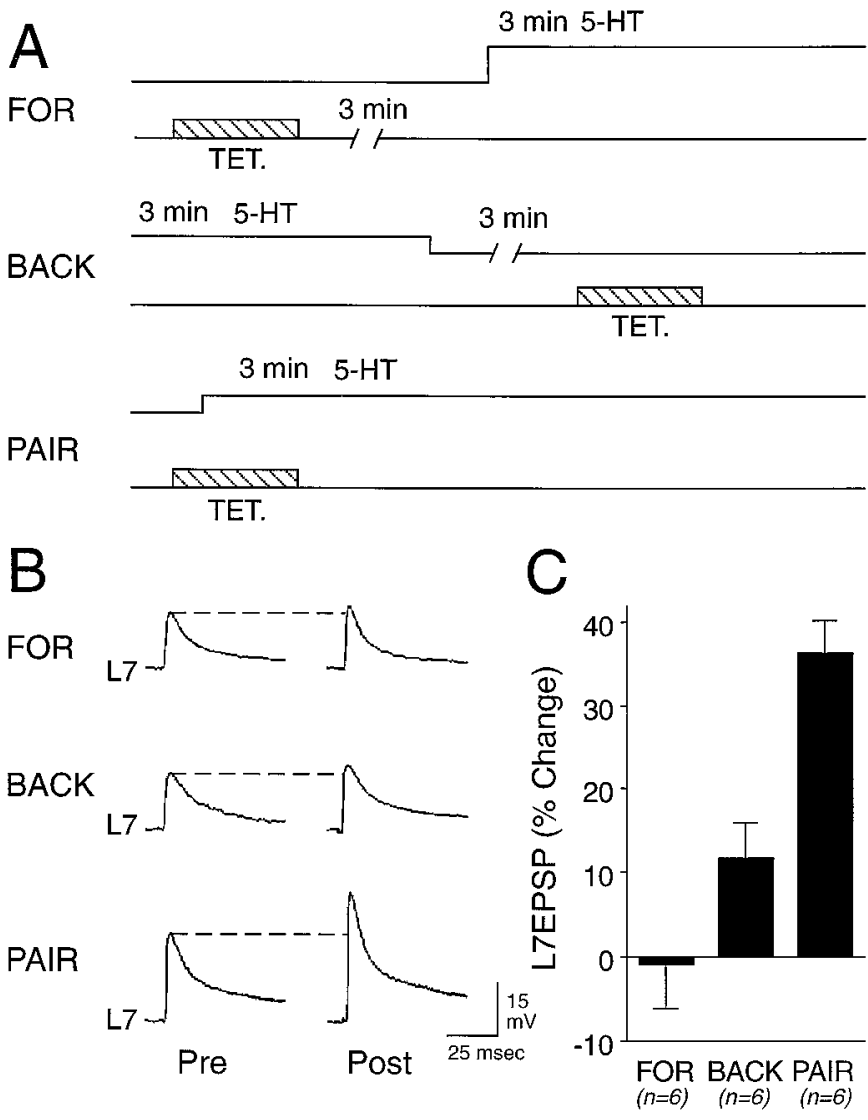

Figure 3. Tetanus plus 5-HT applied to both the SN cell body and terminal region must be paired temporally to evoke long-term facilitation. $A$, Schematic representation of the experimental procedures. Tetanus and 5-HT application are separated by 3 min during the forward $(F O R)$ or backward $(B A C K)$ application of the two stimuli. $B$, Examples of EPSPs evoked before (Pre) and $24 \mathrm{hr}$ after (post) treatments. $C$, Summary of the percentage of change in EPSP amplitude 24 hr after pairing or unpairing tetanus with 5-HT ( $n=6$ for each group). Temporally paired stimuli evoked significant changes (ANOVA; $F_{(2,15)}$ $=17.908 ; p<0.001)$ as compared with the other treatments (Scheffé's $F=17.323, p<0.01$ vs forward application of stimuli; $F=7.528, p<$ 0.01 vs backward application of stimuli).

change in the efficacy of sensorimotor connections (Fig. 3). In another set of cultures we compared the change in EPSP amplitude evoked $24 \mathrm{hr}$ after paired stimulation with that evoked when the two stimuli were unpaired in either a "forward" or "backward" sequence (Fig. 3A). Overall, there was a significant change with treatment. Paired stimulation evoked a significant change in the EPSP amplitude of $36.2 \pm 4.0 \%$ (Fig. $3 B, C$ ) as compared with the change of $-1.0 \pm 5.1 \%$ evoked when tetanus to the $\mathrm{SN}$ preceded a $3 \mathrm{~min}$ application of 5 -HT by $3 \mathrm{~min}(F O R ; p<0.01)$ and as compared with the change of $11.7 \pm 4.2 \%$ evoked when tetanus to the $\mathrm{SN}$ was given 3 min after the application of 5-HT (BACK; $p<0.01)$.

\section{Long-term structural changes are evoked by pairing tetanus in the SN and 5-HT activation of receptors on both the $\mathrm{SN}$ cell body and terminal region}

Long-term change in the efficacy of the connection in the intact animal evoked by repeated sensitizing stimuli or in cell culture evoked with repeated (four or five) bath applications of 5-HT is accompanied by an increase in the number of SN varicosities with active zones (Bailey and Chen, 1983, 1988; Glanzman et al., 1990;
Bailey et al., 1992; Bartsch et al., 1995; Zhu et al., 1995, 1997). In cell culture the number of SN varicosities contacting the proximal axon of L7 is strongly correlated with the amplitude of the EPSP. Unlike SN varicosities contacting distal motor neurites, SN varicosities in contact with the proximal motor axon have active sites for transmitter release (Glanzman et al., 1990; Schacher et al., 1990a, 1993; Schacher and Montarolo, 1991; Bailey et al., 1992). After repeated bath applications of 5-HT, significant structural changes in the arbor of the $\mathrm{SN}$, including the formation of new $\mathrm{SN}$ varicosities with active zones, were detected primarily at sites contacting the proximal motor axon (Glanzman et al., 1990; Schacher et al., 1990a). We therefore examined in another set of cultures whether change in the number of SN varicosities that contact the proximal axon of L7 also accompanies long-term functional changes evoked by a single pairing of a tetanus with 5-HT to both the SN cell body and terminal region.

An increase in the number of $\mathrm{SN}$ varicosities contacting the axon of L7 also accompanies long-term facilitation of sensorimotor connections after a single pairing of a tetanus to the SN and 5-HT applied to both the SN cell body and terminal region (Fig. 4). A single pairing evoked a significant change of $34.8 \pm 4.3 \%$ in the EPSP amplitude $24 \mathrm{hr}$ after treatment (Fig. 4A,B). The increase in synaptic efficacy evoked by the paired stimuli is accompanied by a significant increase of $6.0 \pm 0.9$ varicosities in the number of $\mathrm{SN}$ varicosities in contact with the proximal axon of L7 (Figs. $4 C, 5$ ). The increase in EPSP amplitude is significantly greater $(p<0.01)$ than the percentage of change in EPSP amplitude and in the number of SN varicosities evoked with the application of Fast Green alone (CONT), $1.1 \pm 4.6 \%$ and $0.2 \pm$ 1.1 varicosities, respectively. The changes are significantly greater as well than was the change of $1.9 \pm 4.5 \%$ and $0.8 \pm 0.6$ varicosities $(p<0.01)$ evoked with tetanus to the SN paired with control application of Fast Green (TET) or the change of $2.9 \pm$ $4.6 \%$ and $0.8 \pm 0.7$ varicosities $(p<0.01)$ evoked with 5 -HT application alone to both $\mathrm{SN}$ cell body and terminal region (5-HT). Pairing tetanus with an application of 5-HT either to the SN cell body alone $(n=3)$ or the SN terminals along the proximal motor axon alone $(n=3)$ failed to evoke a significant change in EPSP amplitude (average $<10 \%$ ) or in the number of SN varicosities (average of 1.0 and 0.3 varicosities, respectively) (data not shown). Thus, long-term structural changes in the number of SN varicosities contacting the proximal motor axon are associated with a change in EPSP amplitude and are evoked with a single pairing of tetanus and 5-HT binding receptors on both the $\mathrm{SN}$ cell body and $\mathrm{SN}$ terminals contacting the proximal motor axon.

\section{Structural changes in SN accompany long-term facilitation evoked by repeated applications of 5-HT when 5-HT activates receptors on both the SN cell body and terminal region}

In the intact nervous system, long-term facilitation can be evoked in a cell-specific manner by repeated applications of 5-HT to the cell body of the SN (Clark and Kandel, 1993; Emptage and Carew, 1993). We reexamined this issue in cell culture and extended the analysis to determine whether all long-term changes in synaptic efficacy were accompanied by structural plasticity.

Repeated applications of 5-HT to either the SN cell body or to both the SN cell body and terminal region evoked a long-term change in the amplitude of the EPSP evoked $24 \mathrm{hr}$ after treatment (Fig. 6A,B). Control treatment (four applications of Fast Green; $C O N T$ ) and four applications of 5-HT to the terminal regions $(T E R M)$ evoked insignificant changes of $0.8 \pm 3.2 \%$ and $5.1 \pm$ 

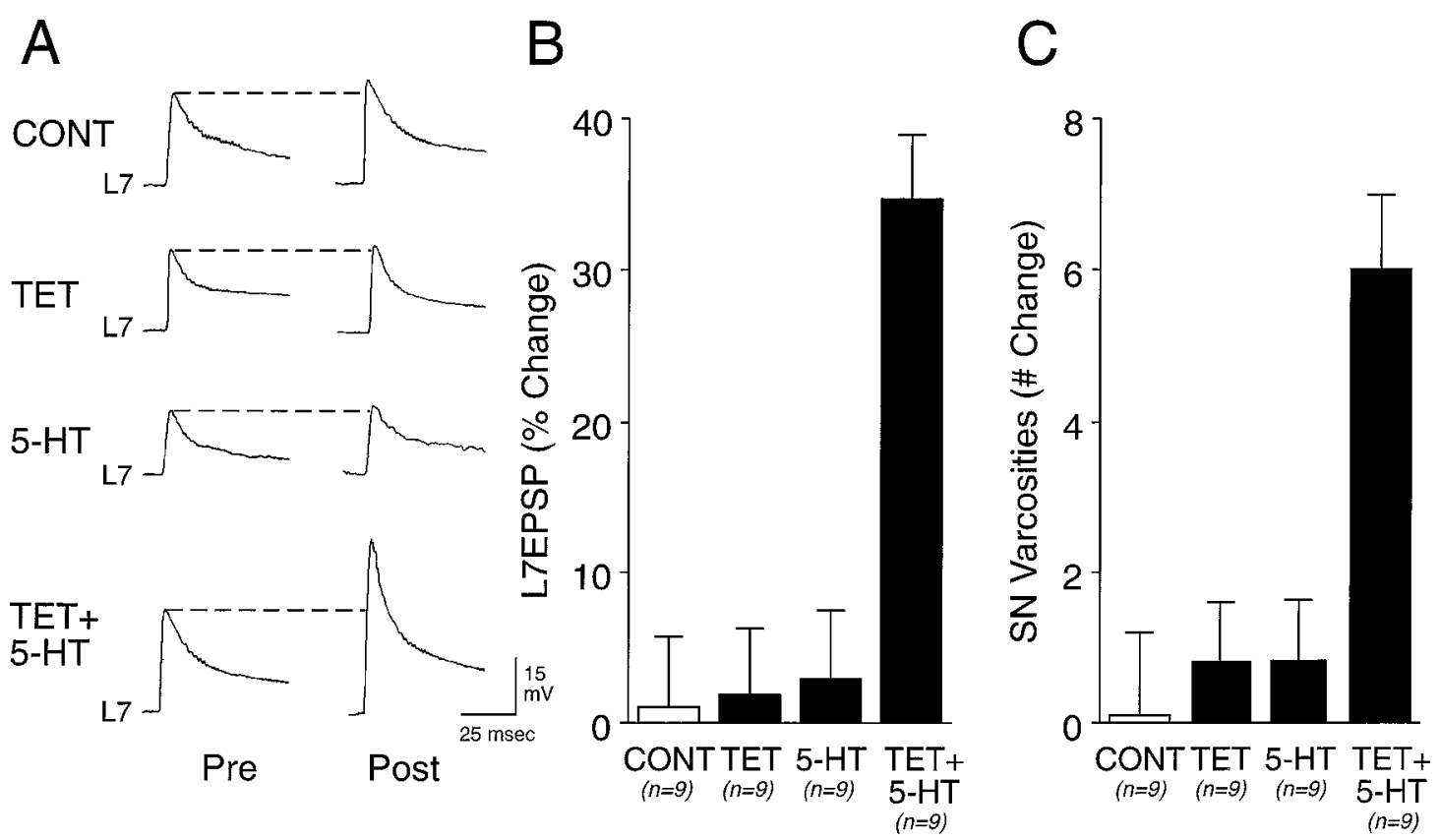

Figure 4. Tetanus plus 5-HT applied to both the SN cell body and terminal region evoked long-term functional and structural changes. All solutions were applied to both the SN cell body and terminal region. A, Examples of EPSPs evoked before (Pre) and 24 hr after (Post) $1 \times$ application of control solution (CONT, Fast Green), $1 \times$ pairing of tetanus with control solution (TET), $1 \times$ application of 5-HT (5-HT), or $1 \times$ tetanus paired with 5-HT (TET $+5-H T)$. B, Summary of the percentage of change in EPSP amplitude after treatments $(n=9$ cultures for each treatment $)$. ANOVA $\left(F_{(3,32)}=15.202\right.$; $p<0.001$ ) indicated an overall effect of treatment. Scheffé's $F$ tests indicated that only pairing tetanus with 5-HT evoked a significant change as compared with other treatments $(F=11.028, p<0.01$ vs control; $F=9.319, p<0.01$ vs tetanus; $F=8.125, p<0.01$ vs 5 -HT). $C$, Summary of the net change in SN varicosities after treatment (same cultures as $B)$. ANOVA $\left(F_{(3,32)}=10.727 ; p<0.001\right)$ indicated an overall effect of treatment. Scheffé's $F$ tests indicated that only pairing tetanus with 5-HT evoked a significant change as compared with other treatments $(F=7.703, p<0.01$ vs control; $F=6.924$, $p<0.01$ vs tetanus; $F=6.725, p<0.01$ vs $5-\mathrm{HT})$.

$3.0 \%$ in the EPSP amplitude, respectively. By contrast, four applications to the $\mathrm{SN}$ cell body $(C B)$ or four applications to both the $\mathrm{SN}$ cell body and terminal region $(C B+T E R M)$ evoked changes of $50.1 \pm 6.3 \%$ and $39.2 \pm 3.7 \%$, respectively. The change evoked with applications to the SN cell body is significantly greater than the change evoked by control treatment $(p<$ $0.01)$ or applications of 5-HT to the terminal region alone $(p<$ $0.01)$. Similarly, the change evoked with applications of 5-HT to both regions is significantly greater than the change evoked by control treatment $(p<0.01)$ or by applications of 5 -HT to the terminal region alone $(p<0.02)$. There is no significant difference between the changes evoked by 5 -HT applications to the SN cell body or 5-HT applications to both the $\mathrm{SN}$ cell body and terminal region $(p>0.2)$.

Although applications of 5-HT to the SN cell body evoked a significant change in the amplitude of the EPSP (and slightly greater than application to both the $\mathrm{SN}$ cell body and terminal region), it failed to evoke a significant change in the number of SN varicosities in the proximal part of the SN arbor contacting the axon of L7 (Fig. 6C). A significant increase of $5.9 \pm 1.3 \mathrm{SN}$ varicosities was observed only with applications of 5-HT to both the SN cell body and terminal region. After control treatment there was a change of $0.6 \pm 1.2$ varicosities. This is not significantly different from the change of $1.2 \pm 0.8$ varicosities after repeated applications of 5-HT to the $\mathrm{SN}$ cell body alone or to a change of $-1.0 \pm 0.5$ varicosities after repeated applications to the terminal region of the $\mathrm{SN}$ alone (Figs. $6 C, 7$ ). Thus, long-term changes in the efficacy of the connection lasting $>24 \mathrm{hr}$ can be evoked in some cases without significant changes in the SN structure in contact with the proximal motor axon. The expres- sion of these structural changes in the $\mathrm{SN}$, however, requires the activation of 5-HT receptors on both the $\mathrm{SN}$ cell body and terminal region.

\section{DISCUSSION}

Our results indicate that different external stimuli presented to a pair of identified neurons and their synaptic connection can evoke equivalent changes in the efficacy of the connections lasting $24 \mathrm{hr}$. Some forms of long-term facilitation of Aplysia sensorimotor synapses require the activation of receptors at multiple sites and are accompanied by net increases in the number of SN varicosities. The formation of new $\mathrm{SN}$ varicosities is correlated with changes in synaptic efficacy (see also Glanzman et al., 1990; Schacher and Montarolo, 1991; Bailey et al., 1992; Schacher et al., 1993) and requires the activation of 5-HT receptors on both the $\mathrm{SN}$ cell body and terminal regions. The formation of these new $\mathrm{SN}$ varicosities could contribute to changes in synaptic efficacy, because previous studies indicate that new varicosities contacting the proximal motor axon have transmitter release sites (Glanzman et al., 1989, 1990; Schacher et al., 1990a). Changes in synaptic function after $24 \mathrm{hr}$ also are expressed without changes in the number of $\mathrm{SN}$ varicosities contacting the proximal motor axon when 5-HT receptors on the SN cell body alone are activated repeatedly. Applications of 5-HT to the SN terminal region alone evoke no long-term change in efficacy or in the number of $\mathrm{SN}$ varicosities contacting the proximal motor axon.

Our data suggest that SN synapses may express different forms of long-term facilitation via differential activation of local 5-HT receptors and their signal transduction machinery. In the intact nervous system two populations of serotonergic varicosities inter- 


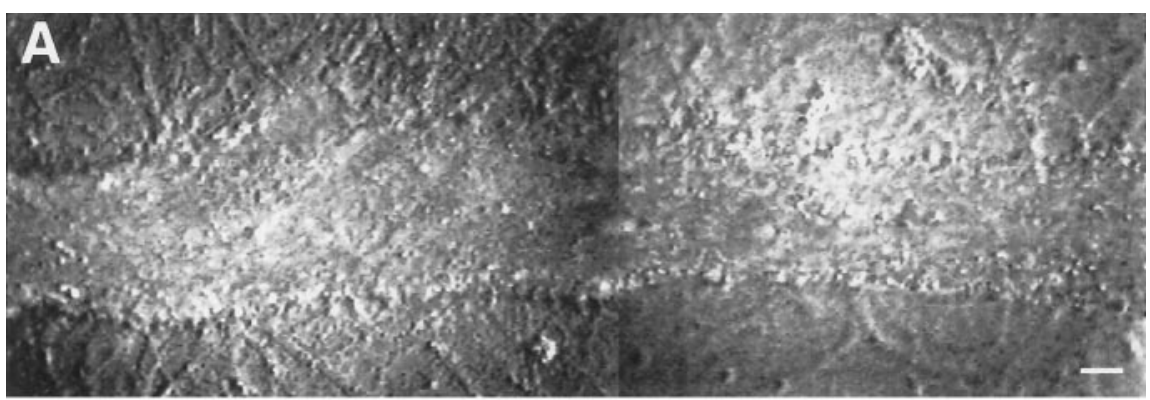

Figure 5. Structural changes are evoked by pairing tetanus and 5-HT application to both the SN cell body and terminal region. $A$, Nomarski contrast view of a portion of the motor axon where $\mathrm{SN}$ forms numerous varicosities. Scale bar, $5 \mu \mathrm{m}$. $B$, Epifluorescent view of the same view area as in $A$, depicting SN neurites and varicosities in contact with the motor axon before stimulation. Two focal planes were superimposed to permit the visualization of all neurites and varicosities. $C$, Epifluorescent view of the same view area as in $B 24 \mathrm{hr}$ after stimulation. Note four new SN branches (arrows), with each containing new varicosities (some are indicated with thick arrows) There was a net increase of nine varicosities in this region of SN-L7 interaction. The EPSP amplitude increased by $50 \%$ (from 20 to $30 \mathrm{mV}$ ). No net change in $\mathrm{SN}$ varicosities was observed when tetanus was paired with 5-HT application to the $\mathrm{SN}$ cell body alone or to the terminal region alone.
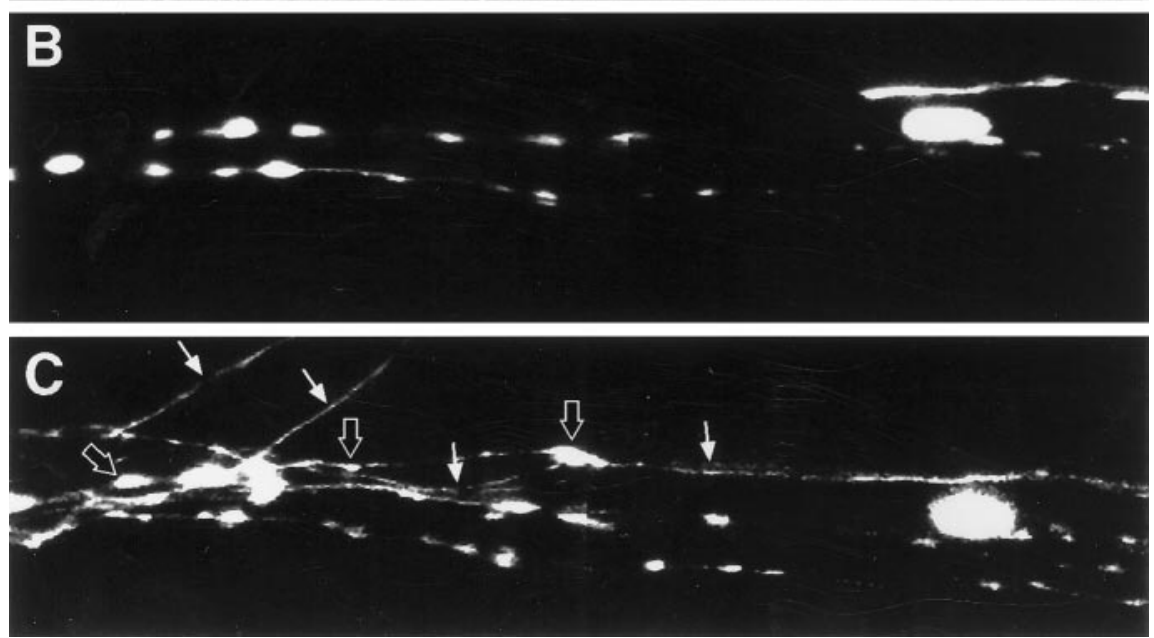

act with SNs: those contacting SN cell bodies directly and those contacting distant SN neurites and varicosities (Kistler et al., 1985; Zhang et al., 1991). These two sites also appear to express different populations or mixtures of 5-HT receptor subtypes (Mercer et al., 1991; Emptage and Carew, 1993; Sun and Schacher, 1996; Sun et al., 1996). If these two populations of serotonergic varicosities are activated differentially by external stimuli, our results suggest that $\mathrm{SN}$ synapses could express different forms of long-term facilitation that could lead to different behavioral outcomes.

The changes evoked with a single pairing of tetanus and 5-HT to both cell body and terminals are likely to be mediated by the
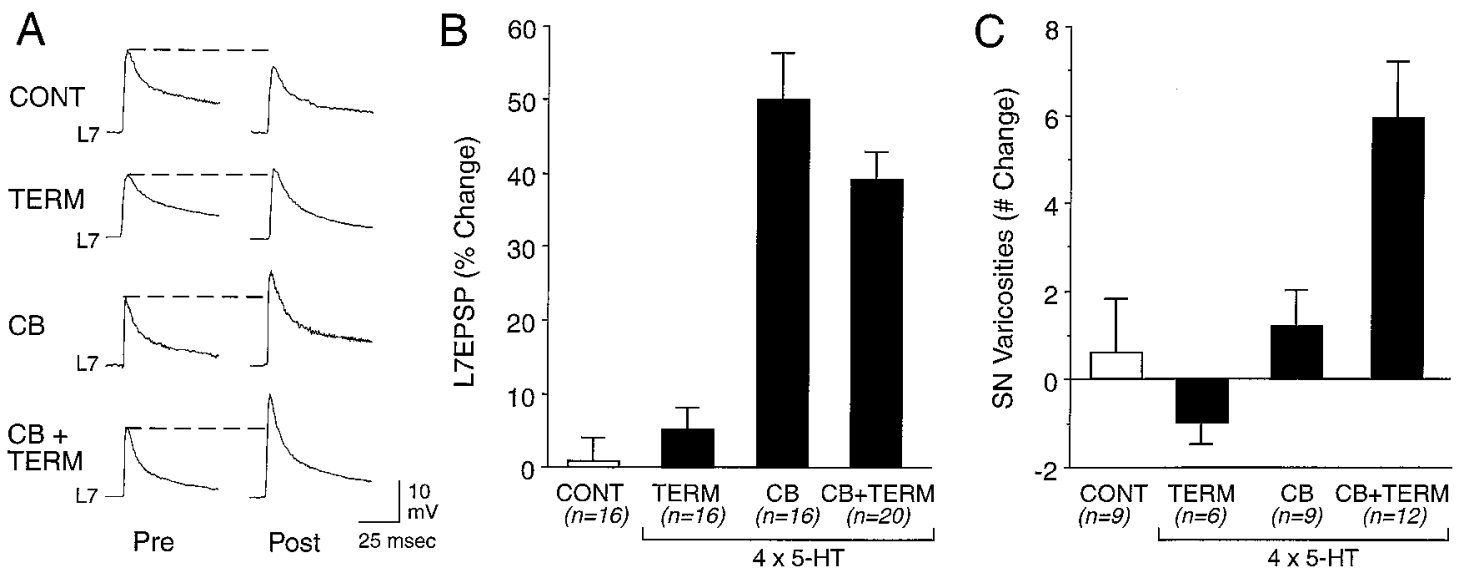

Figure 6. Long-term changes in synaptic efficacy and SN structure with $4 \times$ applications of 5-HT to different areas of SN-L7 interaction. $A$, Examples of changes in EPSP evoked before (Pre) and $22 \mathrm{hr}$ after (Post) $4 \times$ applications of control solution (Fast Green) to the SN cell body and terminal region $(C O N T)$ or $4 \times$ application of 5-HT to the terminal region (TERM), SN cell body $(C B)$, or both the cell body and terminal region $(C B+T E R M)$. $B$, Summary of the percentage of change in EPSP amplitude $22 \mathrm{hr}$ after $4 \times$ applications of control or experimental treatments. ANOVA $\left(F_{(3,64)}=31.504\right.$; $p<0.001)$ indicated an overall effect of treatment. Scheffé's $F$ tests indicated that applications of 5-HT to the cell body alone ( $C B, n=16$ cultures) evoked significant changes as compared with control $(C O N T, n=16$ cultures; $F=21.375 ; p<0.01)$ or 5-HT applications to the terminal region alone $(T E R M$, $n=16$ cultures; $F=16.653 ; p<0.01)$. Applications of 5-HT to both cell body and terminal region $(C B+T E R M, n=20)$ evoked significant changes as compared with control treatment $(F=13.940 ; p<0.01)$ or 5 -HT applications to the terminal region alone $(F=10.124, p<0.01)$. $C$, Summary of the net change in SN varicosities $22 \mathrm{hr}$ after $4 \times$ applications of control or experimental treatments for a subset of the cultures examined in $B$. ANOVA $\left(F_{(3,32)}=8.377 ; p<0.001\right)$ indicated an overall effect of treatment. Scheffé's $F$ tests indicated that only applications of 5-HT to both regions evoked a significant change in the number of SN varicosities as compared with controls $(F=4.177 ; p<0.03), 5$-HT applications to the SN cell body alone $(F=$ $3.153 ; p<0.05)$, or applications to the terminal region alone $(F=5.733 ; p<0.01)$. 

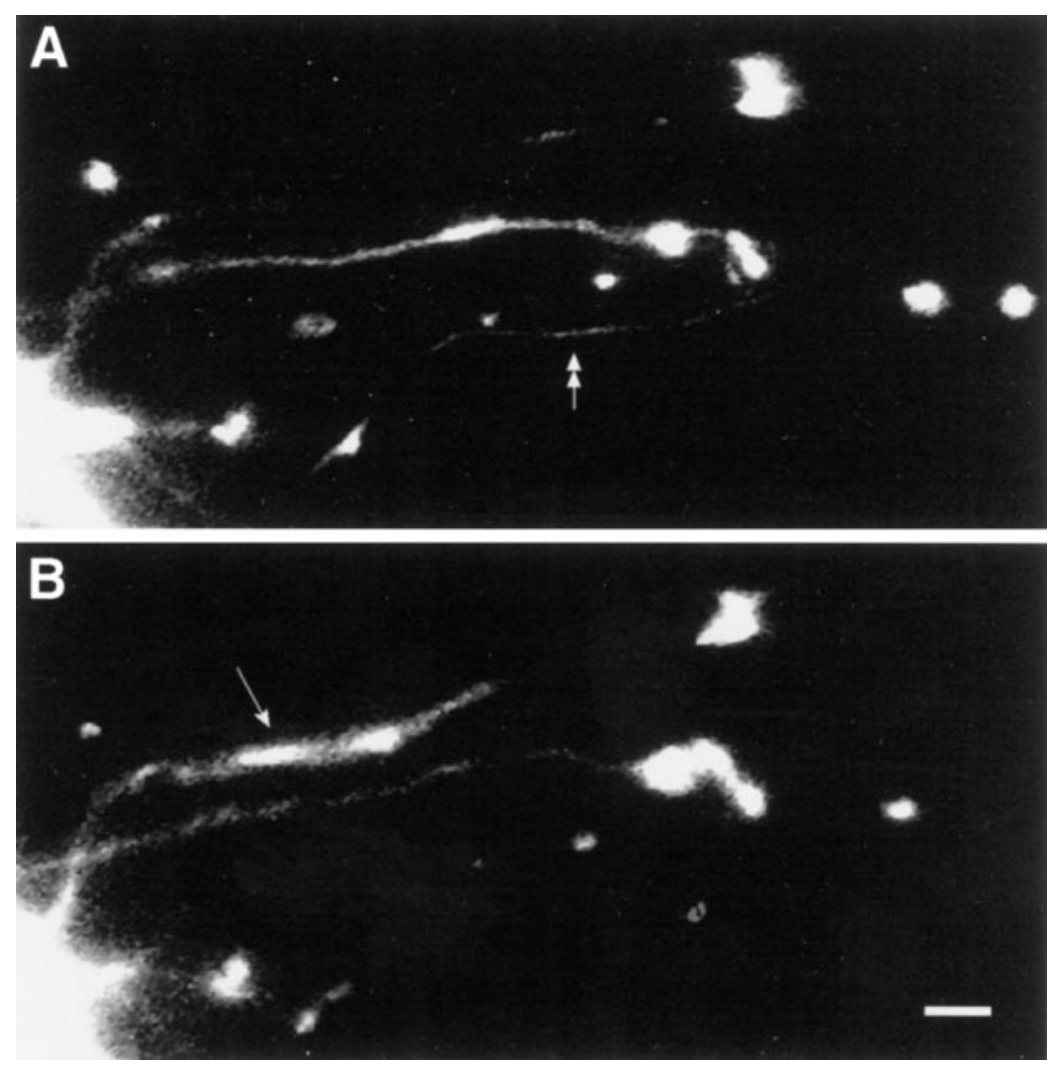

Figure 7. Repeated applications of 5-HT to the terminal region failed to evoke a net change in $\mathrm{SN}$ varicosities. $A$, Epifluorescent view of a portion of SN neurites and varicosities contacting a motor axon (right to left in the middle half of the micrograph) before stimulation $(4 \times 5$-HT to the terminal region). Three focal planes were superimposed to permit the visualization of all neurites and varicosities. A double arrow points to a neurite that retracts, because it is absent after $24 \mathrm{hr}$ (see $B$ ). $B$, Epifluorescent view of the same view area as in $A$ $22 \mathrm{hr}$ after the last 5-HT application. The arrow points to the branch that extended after treatment. The number of varicosities is unchanged after treatment. Scale bar, $5 \mu \mathrm{m}$.

same cellular and molecular events as those evoked with repeated applications of 5-HT alone (Hawkins et al., 1983; Walters and Byrne, 1983; Buonomano and Byrne, 1990; Eliot et al., 1994; Bao et al., 1997; Schacher et al., 1997). The temporal coincidence of activity in the $\mathrm{SN}$ and 5-HT binding to receptors on the $\mathrm{SN}$ increases the levels of cAMP produced by adenylyl cyclase (Occor et al., 1985; Abrams et al., 1991). The large increase in cAMP levels in the SN cell body and terminals with a single pairing may parallel the large changes in cAMP levels evoked with repeated applications of 5-HT or with the injection of cAMP directly into the SN. Such large changes in cAMP levels may be required to trigger the appropriate changes in expression (both up and down) of transcription factors and other genes that influence the synthesis of effector proteins responsible for the changes in excitability, synaptic transmission, and the structure SNs (Dale et al., 1987; Scholz and Byrne, 1988; Dash et al., 1990; Nazif et al., 1991; Backsai et al., 1993; Kaang et al., 1993; Schacher et al., 1993; Alberini et al., 1994; Bartsch et al., 1995). By contrast, the cAMPdependent processes evoked by pairing activity with a single application of 5-HT to the SN cell body alone may be below the threshold that is required for initiating the cascade of events leading to long-term changes in cellular properties (Schacher et al., 1990b; Bartsch et al., 1995; Ghirardi et al., 1995).

In addition to changes in the SN cell body, timely activation of signal transduction machinery in the $\mathrm{SN}$ terminals and L7 axon is likely to contribute to long-term structural and functional changes. The binding of 5-HT to receptors in the terminal region that are linked to both the adenylyl cyclase-PKA pathway and the phospholipase C-PKC pathway (Saktor and Schwartz, 1990; Goldsmith and Abrams, 1991; Ghirardi et al., 1992; Sossin and Schwartz, 1992; Sugita et al., 1992; Li et al., 1995; Sun and Schacher, 1996) may contribute to the initiation of the structural changes in the presynaptic SN. A transient increase in PKC activity with phorbol ester leads to transient changes in synaptic efficacy and in the structure of $\mathrm{SN}$ neurites and varicosities contacting motor cell L7 (Wu et al., 1995). These local changes at presynaptic $\mathrm{SN}$ terminals plus inductive events in the $\mathrm{SN}$ cell body mediated by the cAMP-PKA pathway may contribute to the expression of the various presynaptic and postsynaptic components of long-term plasticity.

The results reported here extend earlier studies on the sitespecific actions of neuromodulators (Clark and Kandel, 1984, 1993; Hammer et al., 1989; Emptage and Carew, 1993; Sun et al., 1996) and suggest that 5-HT receptors required for the expression of different features of long-term facilitation are distributed in a nonuniform manner. To evoke short-term plasticity with a single application of neuromodulator, 5-HT must bind receptors at or near $\mathrm{SN}$ varicosities to mediate short-term changes in synaptic efficacy and must bind receptors at the cell body to mediate short-term changes in excitability (Clark and Kandel, 1984; Emptage and Carew, 1993; Sun et al., 1996). By contrast, our results indicate that repeated applications of 5-HT $(50 \mu \mathrm{M})$ to the terminal region of SNs failed to evoke any long-term change, whereas applications to the $\mathrm{SN}$ cell body alone evoked only long-term functional changes in SN connections. This result differs in part from those results obtained with applications of 5-HT to terminal regions of SNs in the intact nervous system. Relatively high levels of exogenous 5-HT applied to SN terminal region can evoke a long-term change in synaptic efficacy (Clark and Kandel, 1993; Emptage and Carew, 1993). In those studies, however, it is difficult to rule out low levels of release from 5-HT-filled varicosities that surround SN cell bodies (Kistler et al., 1985; Zhang et al., 1991) or the release of other neuromodulators from interneurons during the $24 \mathrm{hr}$ incubation (Hawkins et al., 1981; Abrams et al., 1984; Pieroni and Byrne, 1992) that may contribute to longterm functional changes when coupled with the local actions of 
exogenous applications of 5-HT. Recently, Martin et al. (1997a) reported that repeated local applications of 5-HT to the terminal region of one set of $\mathrm{SN}$ synapses can evoke synapse-specific long-term facilitation. The expression of synapse-specific longterm facilitation could be attributable to the high concentration of 5-HT used to evoke long-term facilitation $(100 \mu \mathrm{M})$ or to the properties of a unique population of SNs with two axons that interact with separate postsynaptic targets.

Changes in the efficacy of SN synapses lasting $24 \mathrm{hr}$ can be expressed without net changes in the number of $\mathrm{SN}$ varicosities contacting the proximal motor axon. This raises the possibility that a change in the number of varicosities evoked with other treatments may not contribute to the functional change, because expressing the structural change does not lead to a greater increase in synaptic efficacy. This is not likely. Previous studies, both in the intact animal with sensitizing stimuli and in cell culture with 5-HT applications, indicate that new $\mathrm{SN}$ varicosities contain active zones. Second, the cellular mechanisms underlying the two forms of long-term facilitation may be different. Longlasting functional changes with applications to the SN cell body alone could be mediated by increases in (1) the number of active zones within existing varicosities (Bailey and Chen, 1983), (2) transmitter release at preexisting active zones (Dale et al., 1988), (3) electrical excitability in the presynaptic nerve terminal (Dale et al., 1987; Scholz and Byrne, 1987), or (4) the sensitivity of postsynaptic glutamate receptors at sites with preexisting SN varicosities (Zhu et al., 1997). These changes may be expressed at the terminal region via axonal transport of new gene products synthesized in the SN cell body (Montarolo et al., 1986; Dale et al., 1987; Schacher et al., 1988; Barzilai et al., 1989; Kuhl et al., 1992; Hu et al., 1993; Alberini et al., 1994; Hegde et al., 1997; Liu et al., 1997). By contrast, changes in the number of SN varicosities, a critical feature of long-lasting change in synaptic function (Bailey and Kandel, 1993), require both changes initiated in the $\mathrm{SN}$ cell body as well as local changes in the terminal region of the SNs and the axon of L7 (Trudeau and Castellucci, 1995; Zhu et al., 1995, 1997). Local and targeted second messenger-mediated changes in the organization of the cytoskeleton, in the distribution of intracellular organelles and associated cytoplasmic proteins critical for the formation and processing of synaptic vesicles, in the distribution of cell adhesion molecules enriched at release sites, and in the distribution and sensitivity of postsynaptic glutamate receptors may be initiated by the binding of 5-HT to receptors at or near the $\mathrm{SN}$ varicosities. These local changes may override or inhibit some of the changes evoked by activation of 5-HT receptors on the $\mathrm{SN}$ cell body, leading to equivalent changes in synaptic efficacy. Compensatory presynaptic and postsynaptic changes appear to result in the equivalent expression of synaptic efficacy at developing nerve-muscle synapses in Drosophila (Schuster et al., 1996; Stewart et al., 1996). Future studies will be directed at determining the intracellular pathways by which 5-HT might influence these local changes and the methods by which those changes interact with the events initiated by 5 -HT in the SN cell body in mediating different forms of synaptic plasticity.

\section{REFERENCES}

Abrams TW, Castellucci VF, Camardo JS, Kandel ER, Lloyd P (1984) Two endogenous neuropeptides modulate the gill- and siphonwithdrawal reflex in Aplysia by presynaptic facilitation involving cAMP-dependent closure of a serotonin-sensitive potassium channel. Proc Natl Acad Sci USA 81:7956-7960.

Abrams TW, Karl KA, Kandel ER (1991) Biochemical studies of stim- ulus convergence during classical conditioning in Aplysia: dual regulation of adenylate cyclase by calcium/calmodulin and transmitter. J Neurosci 11:2655-2665.

Alberini CM, Ghirardi M, Metz R, Kandel ER (1994) C/EBP is an immediate-early gene required for the consolidation of long-term facilitation in Aplysia. Cell 76:1099-1114.

Backsai BJ, Hochner B, Mahaut-Smith M, Adams SR, Kaang B, Kandel ER, Tsien RY (1993) Spatially resolved dynamics of cAMP and protein kinase A subunits in Aplysia sensory neurons. Science 260:222-226.

Bailey CH, Chen M (1983) Morphological basis of long-term habituation and sensitization. Science 220:91-93.

Bailey CH, Chen M (1988) Long-term memory in Aplysia modulates the total number of varicosities of single identified sensory neurons. Proc Natl Acad Sci USA 85:2373-2377.

Bailey CH, Kandel ER (1993) Structural changes accompanying memory storage. Annu Rev Physiol 55:397-426.

Bailey CH, Chen M, Montarolo PG, Kandel ER, Schacher S (1992) Inhibitors of protein and RNA synthesis block structural and functional changes accompanying long-term synaptic facilitation and inhibition in Aplysia sensory neurons. Neuron 9:749-758.

Bank M, Schacher S (1992) Segregation of presynaptic inputs on an identified target neuron in vitro: structural remodeling visualized over time. J Neurosci 12:2960-2972.

Bao JX, Kandel ER, Hawkins RD (1997) Involvement of pre- and postsynaptic mechanisms in posttetanic potentiation at Aplysia synapses. Science 275:969-973.

Bartsch D, Ghirardi M, Skehel PA, Karl KA, Herder SP, Chen M, Bailey CH, Kandel ER (1995) Aplysia CREB2 represses long-term facilitation: relief of repression converts transient facilitation into long-term functional and structural change. Cell 83:979-992.

Barzilai A, Kennedy TE, Sweatt JD, Kandel ER (1989) 5-HT modulates protein synthesis and the expression of specific proteins during longterm facilitation in Aplysia sensory neurons. Neuron 2:1577-1586.

Buonomano DV, Byrne JH (1990) Long-term synaptic changes produced by a cellular analog of classical conditioning in Aplysia. Science 249:420-423.

Byrne JH, Zwartjes R, Homayouni R, Critz SD, Erskin A (1993) Roles of second messenger pathways in neuronal plasticity and in learning and memory. In: Advances in second messenger and phosphoprotein research, Vol 27 (Shennolikar S, Nairn AC, eds), pp 47-108. New York: Raven.

Castellucci VF, Kandel ER (1976) Presynaptic facilitation as a mechanism for behavioral sensitization in Aplysia. Science 194:1176-1178.

Clark GA, Kandel ER (1984) Branch-specific heterosynaptic facilitation in Aplysia siphon sensory cells. Proc Natl Acad Sci USA 81:2577-2581.

Clark GA, Kandel ER (1993) Induction of long-term facilitation in Aplysia sensory neurons by local application of serotonin to remote synapses. Proc Natl Acad Sci USA 90:11411-11415.

Dale N, Kandel ER, Schacher S (1987) Serotonin produces long-term changes in the excitability of Aplysia sensory neurons in culture that depend on new protein synthesis. J Neurosci 7:2232-2238.

Dale N, Schacher S, Kandel ER (1988) Long-term facilitation in Aplysia involves increase in transmitter release. Science 239:282-285.

Dash P, Hochner B, Kandel ER (1990) Injection of cAMP responsive element into the nucleus of Aplysia sensory neurons blocks long-term facilitation. Nature 345:718-721.

Eliot LS, Hawkins RD, Kandel ER, Schacher S (1994) Pairing-specific, activity-dependent presynaptic facilitation at Aplysia sensory-motor synapses in isolated cell culture. J Neurosci 14:368-383.

Emptage NJ, Carew TJ (1993) Long-term synaptic facilitation in the absence of short-term facilitation in Aplysia neurons. Science 262:253-256.

Frost WN, Castellucci VF, Hawkins RD, Kandel ER (1985) Monosynaptic connections made by the sensory neurons of the gill- and siphonwithdrawal reflex in Aplysia participate in the storage of long-term memory for sensitization. Proc Natl Acad Sci USA 82:8266-8269.

Ghirardi M, Braha O, Hochner B, Montarolo PG, Kandel ER, Dale N (1992) Roles of PKA and PKC in facilitation of evoked and spontaneous transmitter release at depressed and non-depressed synapses in Aplysia sensory neurons. Neuron 9:1-20.

Ghirardi M, Montarolo PG, Kandel ER (1995) A novel intermediate stage in the transition between short- and long-term facilitation in the sensory to motor neuron synapse of Aplysia. Neuron 14:413-420. 
Glanzman DL, Kandel ER, Schacher S (1989) Identified target motor neuron regulates neurite outgrowth and synapse formation of Aplysia sensory neurons in vitro. Neuron 3:441-450.

Glanzman DL, Kandel ER, Schacher S (1990) Target-dependent structural changes accompanying long-term synaptic facilitation in Aplysia neurons. Science 249:799-802.

Goelet P, Castellucci VF, Schacher S, Kandel ER (1986) The long and short of long-term memory. Nature 322:419-422.

Goldsmith BA, Abrams TW (1991) Reversal of synaptic depression by serotonin at Aplysia sensory neuron synapses involves activation of adenylate cyclase. Proc Natl Acad Sci USA 88:9021-9025.

Greenberg SM, Castellucci VF, Bayley H, Schwartz JH (1987) A molecular mechanism for long-term sensitization in Aplysia. Nature 329:62-65.

Hammer M, Cleary LJ, Byrne JH (1989) Serotonin acts in the synaptic region of sensory neurons in Aplysia to enhance transmitter release. Neurosci Lett 104:235-240.

Hawkins RD, Castellucci VF, Kandel ER (1981) Interneurons involved in mediation and modulation of gill-withdrawal reflex in Aplysia. II. Identified neurons produce heterosynaptic facilitation contributing to behavioral sensitization. J Neurophysiol 45:315-326.

Hawkins RD, Abrams TW, Carew TJ, Kandel ER (1983) A cellular mechanism of classical conditioning in Aplysia: activity-dependent amplification of presynaptic facilitation. Science 219:400-405.

Hegde AN, Inokuchi K, Pei W, Casadio A, Ghirardi M, Chain DG, Martin KC, Kandel ER, Schwartz JH (1997) Ubiquitin C-terminal hydrolase is an intermediate-early gene essential for long-term facilitation in Aplysia. Cell 89:115-126.

$\mathrm{Hu}$ Y, Barzilai A, Chen M, Bailey CH, Kandel ER (1993) 5-HT and cAMP induce the formation of coated pits and vesicles and increase the expression of clathrin light chain in sensory neurons of Aplysia. Neuron 10:921-929.

Kaang B-K, Kandel ER, Grant SGN (1993) Stimuli that produce longterm facilitation in Aplysia sensory neurons activate the transcription of cAMP-responsive genes. Neuron 10:427-435.

Kandel ER, Schwartz JH (1982) Molecular biology of learning: modulation of transmitter release. Science 218:433-443.

Kistler HB, Hawkins RD, Koester J, Steinbusch HWM, Kandel ER, Schwartz JH (1985) Distribution of serotonin-immunoreactive cell bodies and processes in the abdominal ganglion of mature Aplysia. J Neurosci 5:72-80.

Kuhl D, Kennedy TE, Barzilai A, Kandel ER (1992) Long-term sensitization training in Aplysia leads to an increase in the expression of Bip, the major protein chaperone of the endoplasmic reticulum. J Cell Biol 119:1069-1076.

Li XC, Giot JF, Kuhl D, Hen R, Kandel ER (1995) Cloning and characterization of two related serotonergic receptors from the brain and the reproductive system of Aplysia that activate phospholipase C. J Neurosci 15:7585-7591.

Liu QR, Hattar S, Endo S, MacPhee K, Zhang H, Cleary LJ, Byrne JH, Eskin A (1997) A developmental gene (Tolloid/BMP-1) is regulated in Aplysia neurons by treatments that induce long-term sensitization. J Neurosci 17:755-764.

Malenka RC, Kauer JA, Perkel DJ, Mark MD, Kelly PT, Nicholl RA, Waxham NN (1989) An essential role for postsynaptic calmodulin and protein kinase activity in long-term potentiation. Nature 340:554-557.

Martin KC, Casadio A, Bailey CH, Chen M, Zhu H, Kandel ER (1997a) Synapse-specific, transcription-dependent long-term facilitation can be reconstituted in a novel Aplysia sensory-motor neuron culture system. Soc Neurosci Abstr 23:233.

Martin KC, Michael D, Rose JC, Barad M, Casadio A, Zhu H, Kandel ER (1997b) MAP kinase translocates into the nucleus of the presynaptic cell and is required for long-term facilitation in Aplysia. Neuron 18:899-912.

Mercer AR, Emptage NJ, Carew TJ (1991) Pharmacological dissociation of modulatory effects of serotonin in Aplysia sensory neurons. Science 254:1811-1813.

Montarolo PG, Goelet P, Castellucci VF, Morgan J, Kandel ER, Schacher S (1986) A critical period for macromolecular synthesis in long-term heterosynaptic facilitation in Aplysia. Science 234:1249-1254.

Montarolo PG, Kandel ER, Schacher S (1988) Long-term heterosynaptic inhibition in Aplysia. Nature 333:171-174.

Nazif FA, Byrne JH, Cleary LJ (1991) cAMP induces long-term mor- phological changes in sensory neurons of Aplysia. Brain Res 539:324-327.

Occor KA, Walters ET, Byrne JH (1985) Associative conditioning analog selectively increases cAMP levels of tail sensory neurons in Aplysia. Proc Natl Acad Sci USA 82:2548-2552.

O’Leary FA, Byrne JH, Cleary LJ (1995) Long-term structural remodeling in Aplysia sensory neurons requires de novo protein synthesis during a critical time period. J Neurosci 15:3519-3525.

Pieroni JP, Byrne JH (1992) Differential effects of serotonin, FMRFamide, and small cardioactive peptide on multiple, distributed processes modulating sensorimotor synaptic transmission in Aplysia. J Neurosci 12:2633-2647.

Rayport SG, Schacher S (1986) Synaptic plasticity in vitro: cell culture of identified Aplysia neurons mediating short-term habituation and sensitization. J Neurosci 6:759-763.

Saktor TC, Schwartz JH (1990) Sensitizing stimuli cause translocation of protein kinase C in Aplysia sensory neurons. Proc Natl Acad Sci USA 87:2036-2039.

Schacher S (1985) Differential synapse formation and neuritic outgrowth at two branches of the metacerebral cell of Aplysia in dissociated cell culture. J Neurosci 5:2028-2034.

Schacher S, Montarolo PG (1991) Target-dependent structural changes in sensory neurons of Aplysia accompany long-term heterosynaptic inhibition. Neuron 6:679-690.

Schacher S, Proshansky E (1983) Neurite regeneration by Aplysia neurons in dissociated cell culture: modulation by Aplysia hemolymph and the presence of the initial axon segment. J Neurosci 3:2403-2413.

Schacher S, Castellucci VF, Kandel ER (1988) Cyclic AMP evokes long-term facilitation in Aplysia sensory neurons that requires new protein synthesis. Science 240:1667-1669.

Schacher S, Glanzman DL, Barzilai A, Dash P, Grant SGN, Keller F, Mayford M, Kandel ER (1990a) Long-term facilitation in Aplysia: persistent phosphorylation and structural changes. Cold Spring Harb Symp Quant Biol 55:187-202.

Schacher S, Montarolo PG, Kandel ER (1990b) Selective short- and long-term effects of serotonin, small cardioactive peptide, and tetanic stimulation on sensorimotor synapses of Aplysia in culture. J Neurosci 10:3286-3294.

Schacher S, Kandel ER, Montarolo PG (1993) cAMP and arachidonic acid simulate long-term structural and functional changes produced by neurotransmitters in Aplysia sensory neurons. Neuron 10:1079-1088.

Schacher S, Wu F, Sun ZY (1997) Pathway-specific synaptic plasticity: activity-dependent enhancement and suppression of long-term heterosynaptic facilitation at converging inputs on a single target. J Neurosci 17:597-606.

Scholz KP, Byrne JH (1987) Long-term sensitization in Aplysia: biophysical correlates in tail sensory neurons. Science 235:685-687.

Scholz KP, Byrne JH (1988) Intracellular injection of cAMP induces a long-term reduction of neuronal potassium currents. Science 240:1664-1667.

Schuster CM, Davis GW, Fetter RD, Goodman CS (1996) Genetic dissection of structural and functional components of synaptic plasticity. II. Fasciclin II controls presynaptic structural plasticity. Neuron 17:655-667.

Sossin WS, Schwartz JH (1992) Selective activation of $\mathrm{Ca}^{2+}$-activated PKCs in Aplysia neurons by 5-HT. J Neurosci 12:1160-1168.

Stewart BA, Schuster CM, Goodman CS, Atwood HL (1996) Homeostasis of synaptic transmission in Drosophila with genetically altered nerve terminal morphology. J Neurosci 16:3887-3895.

Stoop R, Poo MM (1995) Potentiation of transmitter release by ciliary neurotrophic factor requires somatic signaling. Science 267:695-699.

Sugita S, Goldsmith JR, Baxter DA, Byrne JH (1992) Involvement of protein kinase $\mathrm{C}$ in serotonin-induced spike broadening and synaptic facilitation of sensorimotor connections in Aplysia. J Neurophysiol 68:643-651.

Sun Z-Y, Schacher S (1996) Development of short-term heterosynaptic facilitation at Aplysia sensorimotor synapses in vitro is accompanied by changes in the functional expression of presynaptic serotonin receptors. J Neurophysiol 76:2250-2261.

Sun Z-Y, Kauderer B, Schacher S (1996) Differential distribution of functional receptors for neuromodulators evoking short-term heterosynaptic plasticity in Aplysia sensory neurons. J Neurosci 16:7540-7549. 
Trudeau L-E, Castellucci VF (1995) Postsynaptic modifications in longterm facilitation in Aplysia: upregulation of excitatory amino acid receptors. J Neurosci 15:1275-1284.

Walters ET, Byrne JH (1983) Associative conditioning of single sensory neurons suggests a cellular mechanism for learning. Science 219:405-408.

Wu F, Friedman L, Schacher S (1995) Transient versus persistent functional and structural changes associated with facilitation of Aplysia sensory-motor synapses are second messenger-dependent. J Neurosci 15:7517-7527.

Yin JCP, Del Vecchio M, Zhou H, Tully T (1995) CREB as a memory modulator: induced expression of a dCREB2 activator isoform enhances long-term memory in Drosophila. Cell 81:107-115.
Zhang F, Endo S, Cleary LJ, Eskin A, Byrne JH (1997) Role of transforming growth factor- $\beta$ in long-term synaptic facilitation in Aplysia. Science 275:1277-1279.

Zhang ZS, Fang B, Marshak DW, Byrne JH, Cleary LJ (1991) Serotonergic varicosities make synaptic contacts with pleural sensory neurons of Aplysia. J Comp Neurol 311:259-270.

Zhu H, Wu F, Schacher S (1995) Changes in expression and distribution of Aplysia cell adhesion molecules can influence synapse formation and elimination in vitro. J Neurosci 15:4173-4183.

Zhu H, Wu F, Schacher S (1997) Site-specific and sensory neurondependent increases in postsynaptic glutamate sensitivity accompany serotonin-induced long-term facilitation at Aplysia sensorimotor synapses. J Neurosci 17:4976-4986. 